\title{
Deterioration model of RC beams under marine atmospheric environment
}

\author{
Hongyuan $\mathrm{Guo}^{2}$, Guobing $\mathrm{Li}^{2}$, and Xianglin $\mathrm{Gu}^{1,2^{*}}$ \\ ${ }^{1}$ Key Laboratory of Performance Evolution and Control for Engineering Structures, Ministry of Education, P. R. China \\ ${ }^{2}$ Department of Structural Engineering, College of Civil Engineering, Tongji University, 1239 Siping Rd., Shanghai 200092, P.R. \\ China.
}

\begin{abstract}
This paper primarily proposes a deterioration model of reinforced concrete (RC) beams under marine atmospheric environment. Considering factors including corrosion initiation time, corrosion rate, corrosion non-uniformity and its effects on mechanical performances of steel bars, a comprehensive model was developed for the assessment of mechanical behaviour of RC beams under marine atmospheric environment. Also, to avoid the shortages brought by the classical truss theory, a modified compression field theory (MCFT) was applied to evaluate the effects of stirrups corrosion on the shear capacity of an RC beam. Then, according to a virtual case, the life-cycle performance of an RC beam was predicted through probability density evolution method (PDEM). Results approved the feasibility and effectiveness of the proposed model. Finally, further study work was pointed out.
\end{abstract}

\section{Introduction}

It has brought a large scale of structural degradation and financial loss for reinforced concrete (RC) structures to suffer chloride induced corrosion under marine atmospheric environment, [1,2]. Also, existing studies showed that this corrosion generally performed nonuniformity and random characteristics due to the variations of environment and materials. Thus, many efforts have been made to study the non-uniform corrosion and its effects on structural safety [3-8]. According to [8], the failure probability of a corroded RC beam could increase by $200 \%$ with the consideration of corrosion non-uniformity. This result demonstrates the significance to consider the corrosion nonuniformity.

An effective and feasible deterioration model of RC structures plays an essential role in the life cycle design and maintenance of RC structures under marine atmospheric environment. Although many scholars took attempts to study the non-uniform corrosion and related reliability cases, limited attention has been paid to establish a comprehensive model in predicting the deterioration of mechanical behaviour of RC structures $[9,10]$. In existing reliability analysis, the widely used classical truss theory may underestimate the effect of stirrups on the capacity of an RC beam and then overestimate its failure probabilities.

In this paper, a comprehensive deterioration model was developed to predict the capacities of concrete beams under marine atmospheric environment. According to a virtual case, the life-cycle performance of an RC beam was predicted through probability density evolution method (PDEM), and the feasibility and effectiveness of the proposed model was validated accordingly.

\section{Model for prediction of mechanical behaviour of RC beams under marine atmospheric environment}

\subsection{Prediction of corrosion initiation time}

According to CECS [11], the corrosion initiation time, $t_{0}$ of steel bars in RC structures under marine atmospheric environment can be predicted by Eq. (1) approximately.

$$
t_{0}=\left(c / K_{c l}\right)^{2} \times 10^{-6}
$$

where $c$ denotes the cover thickness of concrete $(\mathrm{mm})$ and $K_{c l}$ is chloride penetration factor which can be calculated through Eq. (2).

$$
K_{c l}=2 \sqrt{D_{c l}} \operatorname{erf}^{-1}\left(1-\frac{M_{c r}}{M_{s}}\right)
$$

where, $D_{c l}$ is chloride diffusion coefficient $\left(\mathrm{m}^{2} / \mathrm{a}\right)$ which can be calculated by Eq. (3); erf is the Gauss error function; $M_{\mathrm{cr}}$ is the critical concentration of chloride ion $\left(\mathrm{kg} / \mathrm{m}^{3}\right) ; M_{\mathrm{s}}$ is the chloride concentration of chloride ion on the concrete surface $\left(\mathrm{kg} / \mathrm{m}^{3}\right) . M_{\text {cr }}$ and $M_{\mathrm{s}}$ can be obtained through Table. 1.

* Corresponding author: gxl@tongji.edu.cn 


$$
\begin{gathered}
D_{c l}=D_{c l, r e f} f_{1}(T) f_{2}(R H) \\
D_{c l, r e f}=10^{(-12.06+2.4 w / c)} \\
f_{1}(T)=\exp \left[\frac{U}{R}\left(\frac{1}{T_{r e f}}-\frac{1}{T_{c}}\right)\right] \\
f_{2}(R H)=\left[1+\frac{(1-R H)^{4}}{\left(1-R H_{c}\right)^{4}}\right]^{-1}
\end{gathered}
$$

where, $D_{\mathrm{cl} \text {,ref }}$ is the reference value of chloride diffusion coefficient $\left(\mathrm{m}^{2} / \mathrm{a}\right) ; f_{1}(T)$ is the temperature factor of chloride diffusion; $f_{2}(\mathrm{RH})$ is the humidity factor of chloride diffusion; $w / c$ is the ratio of water to cement; $U$ is the activation energy for chloride diffusion, 35000 $\mathrm{J} \cdot \mathrm{mol}^{-1} ; R$ is the gas constant, $8.314 \mathrm{~J} \cdot \mathrm{mol}^{-1} \cdot \mathrm{K}^{-1} ; T_{\text {ref }}$ is the reference temperature, $293 \mathrm{~K} ; T_{\mathrm{c}}$ is the actual temperature of concrete $(K)$; $\mathrm{RH}$ is the environmental humidity; $R H_{\mathrm{c}}$ is critical humidity, $75 \%$.

Table 1. Critical concentration of chloride ions.

\begin{tabular}{|c|c|}
\hline $\begin{array}{c}\text { Cubic } \\
\text { strength of } \\
\text { concrete } \\
\text { (MPa) }\end{array}$ & $\boldsymbol{M}_{\mathrm{cr}}\left(\mathbf{k g} / \mathbf{m}^{3}\right)$ \\
\hline 40 & 1.4 \\
\hline 30 & 1.3 \\
\hline$\leq 25$ & 1.2 \\
\hline
\end{tabular}

Table 2. Concentration of chloride ions on concrete surface.

\begin{tabular}{|c|c|}
\hline $\begin{array}{c}\text { Cubic } \\
\text { strength of } \\
\text { concrete } \\
\text { (MPa) }\end{array}$ & $\boldsymbol{M}_{\mathbf{s}}\left(\mathbf{k g} / \mathbf{m}^{\mathbf{3}}\right)$ \\
\hline 40 & 3.2 \\
\hline 30 & 4.0 \\
\hline 25 & 4.6 \\
\hline 20 & 5.2 \\
\hline
\end{tabular}

\subsection{Prediction of corrosion rate}

The time-dependent corrosion rate of rebar is described through corrosion current density $i_{\text {corr }}\left(\mathrm{A} / \mathrm{m}^{2}\right)$ as Eq. (7) [12].

$$
i_{\text {corr }}^{m}(t)=10.39 \cdot \zeta \cdot k_{R H} \cdot k_{D_{0}} \cdot k_{W / C} \cdot \rho_{\text {con }}(t)^{-1.175}
$$

where, $\zeta$ is a modifying factor of weight loss which equals 3 in the case of $\mathrm{W} / \mathrm{C}=0.65$ and equals 5.5 for other cases; $k_{\mathrm{RH}}, k_{\mathrm{D} 0}$ and $k_{\mathrm{w} / \mathrm{c}}$ are the normalized modifying, factor of $i_{\text {corr }}^{\mathrm{m}}(t)$ regarding relative humidity, diameter and water-cement ratio, respectively, whose values are listed in Table $3 ; \rho_{\text {con }}(t)$ is the resistivity of concrete $(\Omega \cdot \mathrm{m})$ which can be measured in actual engineering or calculated by Eqs. (8)-(10).

$$
\rho_{\text {con }}(t)=0.72 \cdot \rho_{0} \cdot\left(\frac{t}{t_{0}}\right)^{n_{\text {res }}^{c}} \cdot k_{T, \text { res }}^{c} \cdot k_{\mathrm{RH}, \text { res }}^{c}
$$

$$
k_{T, \text { res }}^{c}=\left\{\begin{array}{l}
1 /[1+0.025 \cdot(\mathrm{T}-20)], T<20^{\circ} \mathrm{C} \\
1 /[1+0.073 \cdot(\mathrm{T}-20)], T \geq 20^{\circ} \mathrm{C}
\end{array}\right.
$$

$$
\begin{aligned}
\rho_{0}= & (750605 \mathrm{wc}-106228) \\
& \cdot \exp \left[-0.4417 C l-7.7213 S+2889\left(\frac{1}{T_{c}}-\frac{1}{303}\right)\right]
\end{aligned}
$$

where, $t$ is concrete age (a) whose maximum value is 1 ; $t_{0}$ is the concrete age when the resistivity of concrete $\rho_{\mathrm{o}}$ is tested; $n_{\text {res }}^{c}$ denotes the resistivity aging factor which equals $0.23,0.54$ and 0.63 for ordinary portland cement, slag portland cement andvfly-ash portland cement, respectively; $k_{\mathrm{T} \text {,res }}^{\mathrm{c}}$ is the temperature factor of concrete; $k_{\mathrm{RH} \text {,res }}^{\mathrm{c}}$ is the relative humidity factor of concrete as shown in Table 4; $\mathrm{Cl}$ is the chloride content (chloridecement ratio); $S$ is the porosity of saturated concrete.

Table 3. Values of $k_{\mathrm{RH}}, k_{\mathrm{D} 0}$ and $k_{\mathrm{w} / \mathrm{c}}$

\begin{tabular}{|c|c|c|c|c|c|}
\hline $\begin{array}{c}\text { Relative } \\
\text { humidity }\end{array}$ & $\boldsymbol{k}_{\mathbf{R H}}$ & $\begin{array}{c}\text { Diameter } \\
\text { of rebar } \\
(\mathbf{m m})\end{array}$ & $\boldsymbol{k}_{\mathbf{D} 0}$ & $\begin{array}{c}\text { Water- } \\
\text { cement } \\
\text { ratio }\end{array}$ & $\boldsymbol{k}_{\mathbf{W} / \mathbf{C}}$ \\
\hline 0.95 & 0.689 & 10 & 1 & 0.65 & 1.141 \\
\hline 0.85 & 1 & 14 & 0.881 & 0.53 & 1 \\
\hline 0.75 & 1.627 & 16 & 0.731 & 0.4 & 0.367 \\
\hline
\end{tabular}

Table 4. Values of $k_{\mathrm{RH}, \mathrm{res}}^{\mathrm{c}}$

\begin{tabular}{|c|c|}
\hline Relative humidity & $\boldsymbol{k}_{\mathrm{RH}, \mathrm{res}}$ \\
\hline 0.90 & 7.58 \\
\hline 0.80 & 6.45 \\
\hline 0.65 & 3.18 \\
\hline 0.50 & 1.08 \\
\hline
\end{tabular}




\subsection{Non-uniformity model of corrosion}

For uniform corrosion, the residual area of a corroded rebar can be assumed as a circle with the average corrosion depth $p_{\text {av }}(t)$, the average cross-sectional area loss ratio $\eta_{\mathrm{s}}(t)$ and the average residual area $A_{\mathrm{av}}(t)$ which are calculated through Eqs. (11)-(13) respectively [9]

$$
\begin{aligned}
& p_{a v}(t)=0.0116 \int_{0}^{t} i_{\text {corr }}^{\mathrm{m}}(\tau) \mathrm{d} \tau \\
& \eta_{s}(t)=1-\frac{\left[D_{0}-2 p_{a v}(t)\right]^{2}}{D_{0}^{2}} \\
& A_{a v}(t)=\frac{\pi D_{0}^{2}}{4}\left[1-\eta_{s}(t)\right]
\end{aligned}
$$

where $D_{0}$ is the nominal diameter of an uncorroded rebar.

Chloride induced corrosion generally performs nonuniformity because of variations in environmental conditions, concrete properties, and thickness of concrete cover [8,13-16]. Non-uniform corrosion severely impairs the mechanical performance of a corroded rebar, induces a failure in non-critical position and reduces the reliability of a corroded RC beam. Thus, in this paper, corrosion non-uniformity factor $R$ defined as Eq. (12), is adopted to quantify the corrosion non-uniformity of a corroded rebar

$$
R=A_{\text {av }} / A_{\min },
$$

where $A_{\text {av }}$ and $A_{\min }$ are the average and minimum crosssectional area of a corroded rebar, respectively [15]. In addition, it should be noticed that $R$ is a random variable following Gumbel distribution probability density function (PDF) and cumulative distribution function (CDF) of $R$ is written as Eq. (15) and (16) respectively.

$$
\begin{gathered}
f_{R}(R)=\frac{1}{\sigma} \cdot \exp \left\{-\frac{(R-\mu)}{\sigma}-\exp \left[-\frac{(R-\mu)}{\sigma}\right]\right\} \\
F_{R}(R)=\exp \left\{-\exp \left[-\frac{R-\mu}{\sigma}\right]\right\}
\end{gathered}
$$

\begin{tabular}{|c|c|c|c|}
\hline $\begin{array}{c}\text { Average } \\
\text { corrosion } \\
\frac{\text { rate }}{i_{\text {corr }}^{m}} \\
\left(\mu \mathrm{A} / \mathrm{cm}^{2}\right)\end{array}$ & $\begin{array}{c}\text { Rebar } \\
\text { diameter } \\
(\mathrm{mm})\end{array}$ & $\mu$ & $\sigma$ \\
\hline $2.27 \sim 19$ & 10 & $\begin{array}{l}3.35 \eta_{\mathrm{s}} \mathrm{e}^{-0.236 i_{\mathrm{corr}}^{m}} \\
+0.12 \eta_{\mathrm{s}}+1.01\end{array}$ & $0.3371 \eta_{\mathrm{s}}+0.0006$ \\
\hline 19 & $\frac{14}{16}$ & $0.046 \eta_{\mathrm{s}}+1.013$ & $0.2508 \eta_{\mathrm{s}}+0.0011$ \\
\hline
\end{tabular}

where $\mu$ and $\sigma$ are parameters of the Gumbel distribution as listed in Table 5.

Table 5. Distribution parameters of $R$

\subsection{Prediction of mechanical behaviour of corroded rebars}

It is well known that a rising corrosion ratio brings a decline in rebar nominal yield stress, ultimate tensile stress, and ratio of nominal yield tensile stress to ultimate tensile stress [17-20]. However, existing studies show that failure generally happens at the most sever corrosion of a rebar, namely the minimum crosssectional. Considering the minimum cross-sectional area, the strength of a corroded rebar equals that of an uncorroded rebar [21]. On the other hand, a growing corrosion degree of a rebar may cause the deterioration of ultimate strain [3]. Meanwhile, Stewart and Zhang $[22,23]$ found that yield platform of a corroded rebar disappeared when corrosion ratio reached about $20 \%$ to $30 \%$. Thus, $\mathrm{Gu}$ et al. developed a corrosion nonuniformity based mechanical behavior model for corroded bars [13], which can be applied to predict the failure mode transformation of a corroded rebar. According to [13], the yield platform of a corroded rebar would disappear and brittle failure would dominate when its corrosion non-uniformity factor $R$ equals $[R]_{\mathrm{cr}}=$ 1.3[13]. Thus, considering the brittle performance of corroded rebars, the tensile capacity of paralleling $n$ corroded rebars can be calculated through Eq. (17)

$$
\begin{aligned}
F_{y}(t) & =f_{y 0} \cdot \max _{I=1}^{n}\left[i \cdot A_{\min , n+1-i}(t)\right] \cdot H\left(R-[R]_{c r}\right) \\
& +f_{y 0} \cdot\left[\sum_{i=1}^{n} A_{\min , i}(t)\right] \cdot\left\{1-H\left(R-[R]_{c r}\right)\right\}
\end{aligned}
$$

where, $H(\cdot)$ denotes the Heaviside function

$$
H(x)=\left\{\begin{array}{l}
1, x \geq 0 \\
0, x<0
\end{array}\right.
$$

\subsection{Analytical model of mechanical behaviour of RC beams}

Without considering the effects of degrading bond behavior between rebars and concrete, Frangopol, Stewart and Zhang et al. calculate the flexural capacity $M_{\mathrm{u}}(t)$ of a corroded RC beam according to flexural theory directly $[14,15,24]$

$$
M_{\mathrm{u}}(t)=F_{y}(t)\left[h_{0}-\frac{F_{y}(t)}{2 f_{\mathrm{c}} b}\right]
$$

where, $f_{\mathrm{c}}$ is the compressive strength of concrete; $b$ is the width of the beam; $h_{0}$ is the effective height of the beam.

However, due to numerous related factors and complex shear mechanism, the shear capacity of a corroded RC beam remains unclear which still needs more attentions [9]. In this paper, modified compression field theory (MCFT) [25,26], a shear analysis methodology, is applied to predict the shear performances of corroded RC beams. In MCFT, a stressstrain relationship of cracked concrete is employed in 
analyzing, where Eqs. (20), (21) and Fig. 1 are utilized for concrete in compression and; Eq. (22) denotes the stress-strain relationship for concrete in tension.

$$
\begin{gathered}
\sigma_{c 2}=f_{c 2 \max }\left[2\left(\frac{\varepsilon_{2}}{\varepsilon_{0}}\right)-\left(\frac{\varepsilon_{2}}{\varepsilon_{0}}\right)^{2}\right] \\
\frac{f_{c 2 \max }}{f_{c}^{\prime}}=\frac{1}{0.8+170 \varepsilon_{1}} \leq 1.0 \\
\sigma_{c 1}=E_{c} \cdot \varepsilon_{1} \cdot H\left(\varepsilon_{c r}-\varepsilon_{1}\right) \\
+\frac{0.45 f_{t}}{1+\sqrt{500 \varepsilon_{1}}}\left[1-H\left(\varepsilon_{c r}-\varepsilon_{1}\right)\right]
\end{gathered}
$$

where, $\varepsilon_{0}$ is the strain at peak compressive stress of concrete as illustrated in Fig.1a; $f_{\text {c2max }}$ denotes the compressive strength of cracked concrete; $\sigma_{\mathrm{c} 2}$ and $\varepsilon_{2}$ are the principal compressive stress and strain in concrete respectively; $f_{\mathrm{c}}^{\prime}$ is cylinder compressive strength of concrete; $\sigma_{\mathrm{c} 1}$ and $\varepsilon_{1}$ are the principal tensile stress and strain of concrete, respectively; $f_{\mathrm{t}}, \varepsilon_{\mathrm{cr}}$ are the tensile strength and corresponding strain of concrete; $E_{\mathrm{c}}$ is the Young's modulus of concrete.

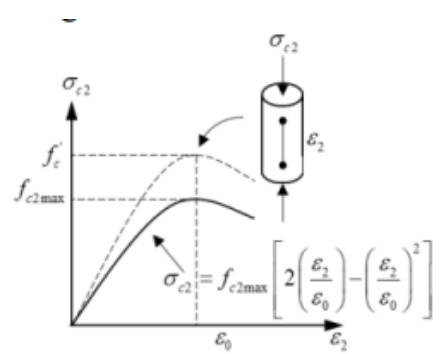

(a)

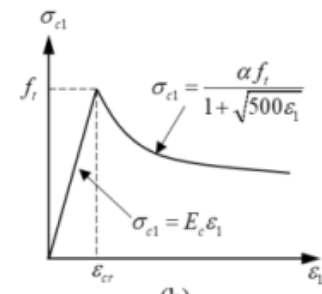

(b)
Fig.1. stress-strain relationship of cracked concrete

Also, Fig.2 shows the stresses distribution in concrete and a free body for the relationship between stirrup stress and concrete stress, where an equilibrium equation can be obtained as follows:

$$
\begin{gathered}
A_{v c} \sigma_{v}=\left(\sigma_{c 2} \sin ^{2} \theta-\sigma_{c 1} \cos ^{2} \theta\right) \cdot b \cdot s \\
\tan ^{2} \theta=\frac{\varepsilon_{x}-\varepsilon_{2}}{\varepsilon_{v}-\varepsilon_{2}}, \varepsilon_{1}=\varepsilon_{x}+\varepsilon_{v}-\varepsilon_{2}
\end{gathered}
$$

where, $A_{\mathrm{vc}}$ are the cross-sectional areas of corroded stirrups; $\varepsilon_{\mathrm{x}}$ and $\varepsilon_{\mathrm{v}}$ are the longitudinal strain and transverse strain respectively.

On the other hand, according to the Mohr's circle of stresses, an equation between $\sigma_{\mathrm{c} 1}$ and $\sigma_{\mathrm{c} 2}$ can be derived:

$$
\begin{gathered}
\sigma_{c 2}=(\tan \theta+\cot \theta) v-\sigma_{c 1} \\
v=\frac{V}{b h}
\end{gathered}
$$

Then, substituting Eq. (25) and (26) into Eq. (23) gives:

$$
V=\sigma_{c 1} b h_{0} \cot \theta+\frac{A_{v c} \sigma_{v}}{s_{v}} h_{0} \cot \theta
$$

where, $s_{\mathrm{v}}$ is the spacing of stirrups.

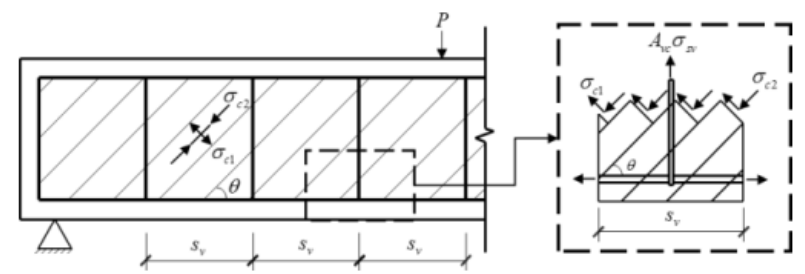

Fig.2 Equilibrium conditions of stresses in a RC beam

As illustrated in Fig.3, the tensile stresses of concrete equal zero at a crack (Fig.3c) but exceed zero at a section between two cracks (Fig.3b). On the other hand, the tensile stresses of steel bars are higher than its average value at a crack (Fig.3c) but lower than its average value at a section between two cracks (Fig.3b). Thus, the shear strength of a beam may be determined by its ability to transmit forces across the crack, viz. local shear stress, $v_{\mathrm{ci}}$, which can be calculated through Eq. (28).

$$
v_{c i}=\frac{0.18 \sqrt{f_{c}^{\prime}}}{0.3+(24 w) /\left(a_{g}+16\right)}
$$

where, $w$ is the crack width; $a_{\mathrm{g}}$ is the maximum aggregate size.

Besides, according to the equilibrium conditions shown in Fig.3, the maximum principal tensile stresses of concrete can be obtained by Eq.(29):

$$
\sigma_{c 1 \max }=v_{c i} \tan \theta+\frac{A_{v c}}{b \cdot s}\left(f_{y v}-\sigma_{v}\right)
$$

In practical engineering, shear stresses vary along the height of a section under the effects of bending moment and shear force. For simplified analysis, uniform shear stress distribution is supposed in this paper $[9,27]$.

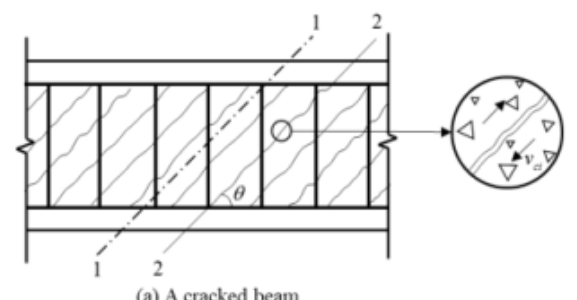

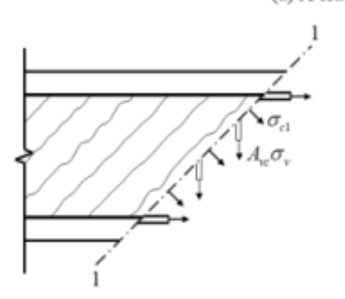

(b) Stresses distribution between two cracks

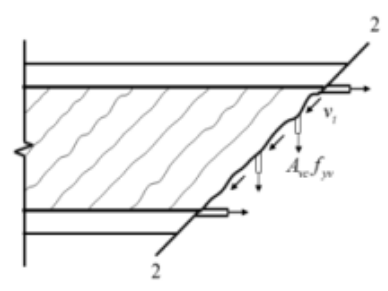

(c) Local stresses at cracks of concrete
Fig.3 Average stresses and local stresses at sections 
However, a computer program for iterative computation is still necessary to solve above equations and obtain the ultimate shear capacity of a RC beam. Generally, being differnt with linear equations, the solutions of non-linear equations are hard to be gained directly. Thus, in this paper, a MATALB program is coded whose detailed algorithm processes are presented in Fig.4.

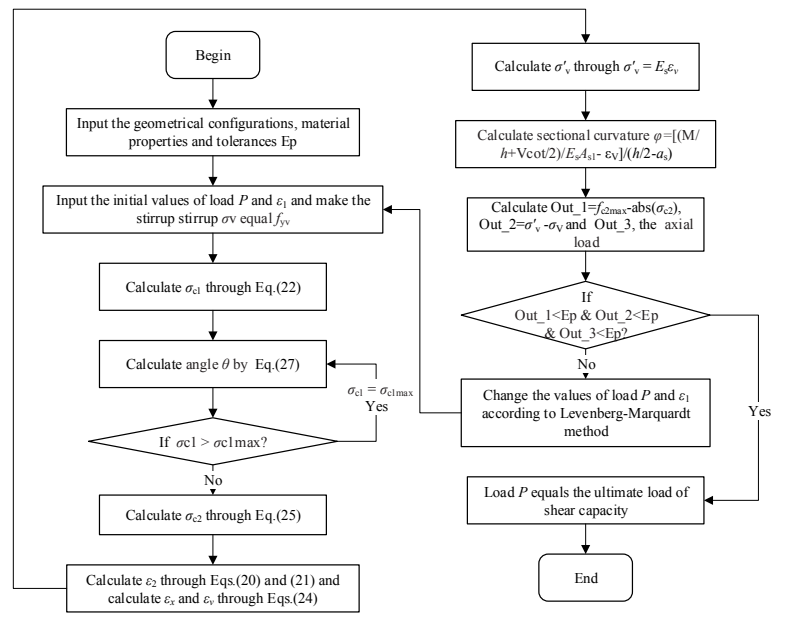

Fig.4 A flow chart to calculate the shear capacity of an $\mathrm{RC}$ beam

\subsection{Verifications for the mechanical model of corroded RC beams}

Experimental results of $\mathrm{Xu}$ [28], Zhao [29] and Higgins [30] are utilized to testify the effectiveness of the proposed analytical model. Detailed information about the geometrical and mechanical properties of $\mathrm{RC}$ beams are listed in Table 6 . Results of 33 cases are illustrated in Fig. 5. It can be found that the ratios of calculation values to experimental ones all fluctuate across 0.97 with 0.15 variation coefficient. Although there exist few deviations between calculation results and actual results, it is still acceptable because probabilistic analytical method can offset this limitation.

\section{Application example}

\subsection{Parameters of RC beam}

Suppose a simply supported beam with a span of $2.4 \mathrm{~m}$ under marine atmospheric environment. The depth, width and cover thickness of the beam is $400 \mathrm{~mm}, 300$ $\mathrm{mm}$ and $25 \mathrm{~mm}$, respectively. Its service life is 50 years. A layout of reinforcement was designed as presented in Fig. 6. Other typical dimensions and details are shown in Table 7 . In addition, this beam locates $0.85 \mathrm{~km}$ far from the coast where temperature is $25{ }^{\circ} \mathrm{C}$ and relative humidity $(\mathrm{RH})$ is $85 \%$. Also, the beam is assumed to suffer four-point loading, as shown in Fig. 6. Other mechaincal parametrs are listed in Table 7.

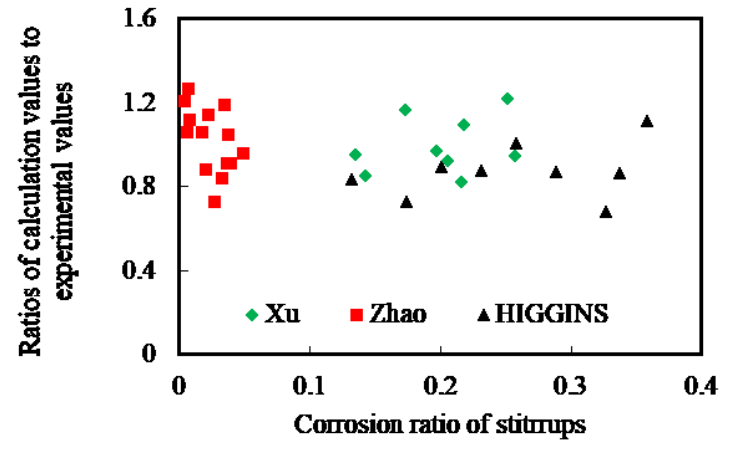

Fig.5 Ratios of calcualtion results to experimental results under different corrosion ratios of sitrrups

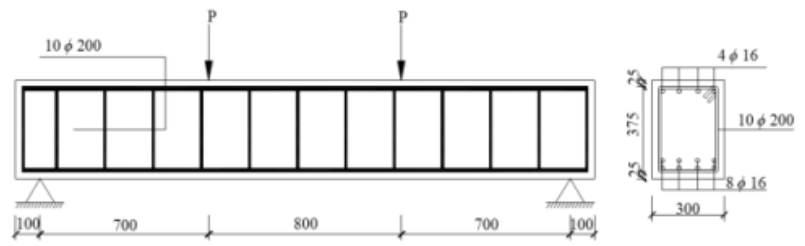

Fig. 6. Dimensions and loading diagram of the RC beam

\subsection{Calculation results}

It is necessary to employ stochastic analysis method to consider the corrosion non-uniformity and its effects on the capacity of the RC beam. However, classical stochastic analysis method, viz. Monte Carlo simulation (MCS), is time consuming which needs a large scale of computing. Therefore, in this paper, probability density evolution method (PDEM) is applied to investigate the probability distribution of the capacity of the beam [31].

Calculation results are illustrated in Fig. 7. It can be seen that this beam suffers a dramatic change on its flexural capacity and shear capacity during its service life, 50 years. At the beginning of the service life, both flexural capacity and shear capacity remain basically unchanged and their variations are pretty small. After about 5 years, the shear capacity starts to decrease (Fig $.7 b$ ), while the flexural ultimate load keeps stable until about tenth year (Fig. 7a). In addition, the shear capacity of the beam drops much more than its flexural capacity. This phenomena may be caused by the thinner cover thickness and the smaller reinforcement ratio of the stirrups.

In general, the deterioration process of the beam can be divided into three phases: steady phase, flexural failure phase and shear failure phase. Fig. 8 presents three typical PDF (probability density function) curves at different phase. It can be found that PDF at 5 year is quite thin and tall which can be regarded as constant variable. PDF at 25 year is shorter and thicker than that at 5 year where the flexural capacity of the beam limits its ultimate capacity. After about 45 years, the shear failure dominates the beam's capacity. It should be noticed that shear failure is brittle failure which should be avoided in practical engineering. The proposed method can be used to predict the shear failure of the beam, which is meaningful for the life-cycle design and maintenance of $\mathrm{RC}$ beams. 
Table 6. Detailed information of corroded RC beams

\begin{tabular}{|c|c|c|c|c|c|c|c|}
\hline $\begin{array}{l}\text { Shear } \\
\text { span } \\
\text { ratio }\end{array}$ & $\begin{array}{c}f_{\mathrm{c}} \\
(\mathrm{MPa})\end{array}$ & $\begin{array}{c}f_{\mathrm{vv}} \\
(\mathrm{MPa})\end{array}$ & $\begin{array}{c}A_{\mathrm{vc}} \\
\left(\mathrm{mm}^{2}\right)\end{array}$ & $\stackrel{\mathrm{s}}{(\mathrm{mm})}$ & $\begin{array}{c}h_{0} \\
(\mathrm{~mm})\end{array}$ & $\begin{array}{c}b \\
(\mathrm{~mm})\end{array}$ & $\begin{array}{c}n_{\mathrm{v}} \\
(\%)\end{array}$ \\
\hline 3.1 & 15 & 331 & 66 & 150 & 145 & 150 & 0.6 \\
\hline 3.1 & 15 & 331 & 66 & 150 & 145 & 150 & 1.8 \\
\hline 3.1 & 15 & 331 & 66 & 150 & 145 & 150 & 2.7 \\
\hline 3.1 & 15 & 331 & 66 & 150 & 145 & 150 & 3.3 \\
\hline 3.1 & 15 & 331 & 66 & 150 & 145 & 150 & 4.0 \\
\hline 3.1 & 15 & 331 & 66 & 100 & 145 & 150 & 0.4 \\
\hline 3.1 & 15 & 331 & 66 & 100 & 145 & 150 & 0.7 \\
\hline 3.1 & 15 & 331 & 66 & 100 & 145 & 150 & 2.2 \\
\hline 3.1 & 15 & 331 & 66 & 100 & 145 & 150 & 3.5 \\
\hline 3.1 & 15 & 331 & 66 & 100 & 145 & 150 & 4.9 \\
\hline 3.1 & 15 & 331 & 101 & 150 & 145 & 150 & 0.8 \\
\hline 3.1 & 15 & 331 & 101 & 150 & 145 & 150 & 2.0 \\
\hline 3.1 & 15 & 331 & 101 & 150 & 145 & 150 & 3.8 \\
\hline 3.1 & 15 & 331 & 101 & 150 & 145 & 150 & 3.8 \\
\hline 3.1 & 15 & 331 & 101 & 150 & 145 & 150 & 3.7 \\
\hline 2 & 34 & 275 & 66 & 150 & 168 & 120 & 21.8 \\
\hline 2 & 33 & 275 & 66 & 150 & 168 & 120 & 19.7 \\
\hline 2 & 32 & 275 & 66 & 150 & 168 & 120 & 21.6 \\
\hline 2 & 34 & 275 & 66 & 150 & 168 & 120 & 20.5 \\
\hline 2 & 33 & 275 & 66 & 150 & 168 & 120 & 25.7 \\
\hline 2 & 32 & 275 & 66 & 150 & 168 & 120 & 13.5 \\
\hline 2 & 34 & 275 & 66 & 150 & 168 & 120 & 17.3 \\
\hline 2 & 33 & 275 & 66 & 150 & 168 & 120 & 25.1 \\
\hline 2 & 32 & 275 & 66 & 150 & 168 & 120 & 14.3 \\
\hline 2.05 & 28 & 331 & 252 & 203 & 521 & 254 & 28.9 \\
\hline 2.05 & 32 & 331 & 252 & 254 & 521 & 254 & 13.3 \\
\hline 2.05 & 32 & 331 & 252 & 254 & 521 & 254 & 23.1 \\
\hline 2.05 & 32 & 331 & 252 & 254 & 521 & 254 & 25.8 \\
\hline 2.05 & 28 & 331 & 252 & 305 & 521 & 254 & 33.8 \\
\hline 2.05 & 35 & 331 & 252 & 254 & 521 & 254 & 20.1 \\
\hline 2.05 & 35 & 331 & 252 & 254 & 521 & 254 & 32.6 \\
\hline 2.05 & 31 & 331 & 252 & 254 & 521 & 254 & 17.4 \\
\hline 2.05 & 31 & 331 & 252 & 254 & 521 & 254 & 35.9 \\
\hline
\end{tabular}

Table 7. Mechanical parameters of the RC beam

\begin{tabular}{|c|c|c|c|}
\hline $\begin{array}{c}\text { Water } \\
\text { cement } \\
\text { ratio }\end{array}$ & $\begin{array}{c}f_{\text {cu }} \\
(\mathrm{MPa})\end{array}$ & $\begin{array}{c}f_{\mathrm{yv}} \\
(\mathrm{MPa})\end{array}$ & $\begin{array}{c}f_{\mathrm{y}} \\
(\mathrm{MPa})\end{array}$ \\
\hline 0.5 & 26 & 360 & 420 \\
\hline
\end{tabular}

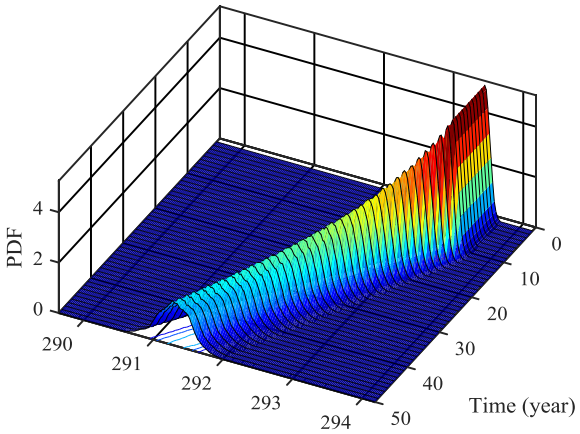

Flexural Ultimate Load $(k N)$

(a)Time-dependent PDF of the flexural ultimate load

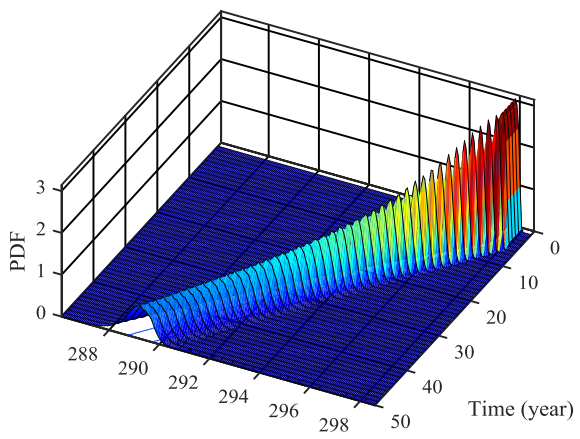

Shear Ultimate Load $(k N)$

(b)Time-dependent PDF of the shear ultimate load

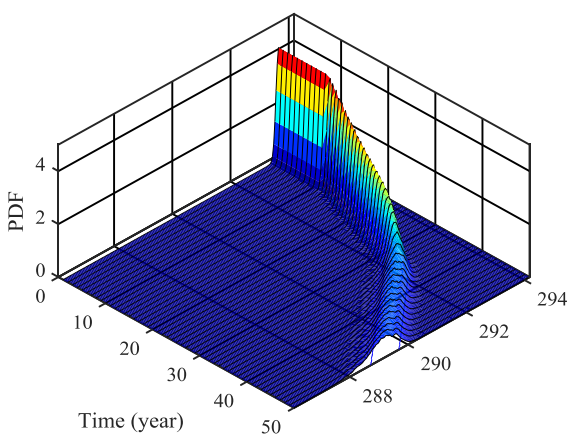

Ultimate Load $(k N)$

(c)Time-dependent PDF of the ultimate load

Fig.7. Calculation results of PDEM

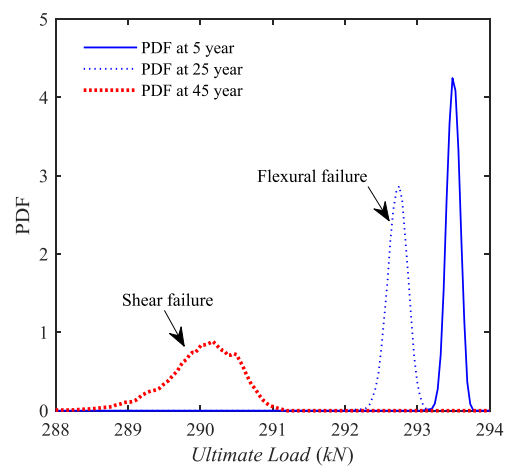

Fig. 8. PDFs at typical times 


\section{Conclusions}

In this paper, a comprehensive deterioration model of RC beams was proposed for life cycle design and maintenance. To begin with, this deterioration model was detailed from the corrosion initiation to mechanical behaviour prediction, where mechanical model of corroded RC was verified by existing experimental results. Then, an application example was utilized to verify the feasibility of the proposed model. Results showed that the suggested model could be used to analyse the mechanical and stochastic deterioration process of an $\mathrm{RC}$ beam under the marine atmospheric environment.

There are still challenges which need further study: (1) a two dimensional diffusion of chloride salt and (2) a corrosion rate model with the consideration of coupling effects of longitudinal bars and stirrups.

The authors gratefully acknowledge the financial support of the National Natural Science Foundation of China (Grant No. 51320105013) and the National Basic Research Program of China (973 program) (Grant No. 2015CB655100).

\section{References}

1. Li C Q, Melchers R E corrosion ACI Struct. J. 102 754-62 (2005)

2. Cairns J, Plizzari G A, Du Y, Law D W, Franzoni C ACI Mater. J. 102 256-64 (2005)

3. Cairns J, Plizzari G a, Du Y, Law D W, Franzoni C ACI Mater. J. 102-M29 256-64 (2005)

4. González J A A, Andrade C, Alonso C, Feliu S. Cem. Concr. Res. 25 257-64 (1995)

5. Rodríguez J, Ortega L M, Casal J. 4th International Symposium on the Corrosion of Reinforcement in Concrete Structures, Cambridge pp 1-10 (1996)

6. Rodriguez J, Ortega L, Casal J Constr. Build. Mater. 11 239-48 (1997)

7. Torres-Acosta A A, Navarro-Gutierrez S, TeránGuillénb J, Terán-Guillén J. Eng. Struct. 29 1145-52 (2007)

8. Stewart M G, Al-Harthy A. Reliab. Eng. Syst. Saf. 93 373-82(2008)

9. Zhang W P, Ye Z W, Gu X L Struct. Infrastruct. Eng. 13 1081-92 (2017)

10. Zhang W P, Ye Z W, Gu X L, Liu X, Li S, Asce M. Struct. Eng. 1434017048 (2017)

11. Standard for durability assessment of concrete structures. CECS. Beijing China Archit. Build. Press (2007)

12. Zhou B B, Gu X L, Guo H Y, Zhang W P, Huang Q H. Constr. Build. Mater. 164 877-87 (2018)

13. Gu X L, Guo H Y, Zhou B B, Zhang W P, Jiang C Eng. Struct. (In Submission) (2017)

14. Stewart M G. Struct. Saf. 26 453-70 (2004)

15. Zhang W P, Zhou B B, Gu X L, Dai H C J. Mater. Civ. Eng. 26 822-32 (2014)
16. Darmawan M S. Mag. Concr. Res. 62 91-101(2010)

17. Du Y G, Clark L a., Chan a. H C, Du Y G. Mag. Concr. Res. 57 135-47 (2005)

18. Dejian S, Reduction D, Shengxing W. Constr. 58-62 (2005)

19. Zhang W P, Song X Bin, Gu X L, Li S B. Constr. Build. Mater. 34 409-17 (2012)

20. Zhang W P, Chen H, Gu X L. Mag. Concr. Res. 68 127-40 (2016)

21. Almusallam A A. Constr. Build. Mater. 15 361-8 (2001)

22. Zhang W P, Shang D F , Gu X L. Tongji Univ. Sci. 5 $586(2006)$

23. Stewart M G. Struct. Infrastruct. Eng. 8 607-19 (2012)

24. Frangopol D M, Lin K, Estes A C. J. Struct. Eng. 123 286-97 (1997)

25. Collins M P, Bentz E C, Sherwood E G, Xie L. Morley Symp. Concr. Plast. - Part II 60 635-50 (2008)

26. Vecchio F J, Collins M P. ACI Struct. J. 85 258-68 (1988)

27. Collins M P, Mitchell D. Prestressed concrete structures vol 9(Prentice Hall Englewood Cliffs, NJ) (1991)

28. $\mathrm{Xu} \mathrm{S} \mathrm{H,} \mathrm{Niu} \mathrm{D} \mathrm{T,} \mathrm{Journal} \mathrm{of} \mathrm{building} \mathrm{structures} 25$ 98-104 (2004)

29. Zhao $Y$ X, Jin $W$ L, Journal of Zhejiang university (Engineering Science) 42 19-24 (2008)

30. Higgins C, Farrow W C, ACI Struct. J. 103 133-141 (2006)

31. Li J, Chen J B. Struct. Saf. 30 65-77 (2008) 